\title{
Observation on the Analgesic Effect of Bilateral Inferior Alveolar Nerve Block Combined With Parecoxib Sodium for Mandibular Orthognathic Surgery
}

\section{Zhang D and Lin J*}

State Key Laboratory of Oral Diseases \& Department of Oral Anesthesia, Sichuan University, China

*Corresponding author: Jie Lin, State Key Laboratory of Oral Diseases \& Department of Oral Anesthesia, West China Hospital of Stomatology, Sichuan University, Chengdu 610041, China, Tel: 86-28-85502116; Email: 514541402@qq.com

\section{Research Article \\ Volume 5 Issue 4}

Received Date: November 25, 2020

Published Date: December 18, 2020

DOI: $10.23880 /$ oajds-16000282

\section{Abstract}

Background: To compare the analgesic effect and safety of bilateral inferior alveolar nerve block combined with parecoxib sodium analgesia and simple intravenous analgesia pump in analgesia after orthognathic surgery.

Methods: Forty patients with simple ascending sagittal split osteotomy and ankle plasty were randomly divided into the experimental group and the control group, with 20 patients in each group. The experimental group received $2 \mathrm{ml} 1 \%$ on both sides. Ropivacaine was treated with inferior alveolar nerve block anesthesia. Immediately after surgery, parecoxib sodium 40 mg was intravenously administered. The control group was given an intravenous analgesia pump for analgesia. Pain intensity (VAS pain score) and Ramsay sedation score were recorded at $2 \mathrm{~h}, 4 \mathrm{~h}, 8 \mathrm{~h}, 24 \mathrm{~h}, 48 \mathrm{~h}$ after operation, and the incidence of postoperative adverse reactions was observed.

Results: There was no significant difference in pain intensity and Ramsay sedation score between the two groups at each time point $(\mathrm{P}>0.05)$. During the analgesic treatment, the incidence of nausea and vomiting $(\mathrm{P}=0.046)$ in the experimental group was significantly lower than that in the control group $(\mathrm{P}<0.05)$.

Conclusion: Bilateral inferior alveolar nerve block combined with parecoxib sodium analgesia and simple intravenous analgesia pump are effective for analgesia after mandibular orthognathic surgery, but the incidence of adverse reactions is significantly lower, more suitable for Analgesia after mandibular orthognathic surgery.

Keywords: Orthognathic surgery; Orthognathic operation of mandible; Inferior alveolar nerve; Nerve block; Postoperative analgesia; Ropivacaine; Parecoxib sodium; Nausea and vomiting

\section{Introduction}

Dentofacial deformity is a common deformity in maxillofacial surgery, and orthognathic surgery is the only treatment method. Orthognathic surgery requires the upper and lower jaws to be cut into sections, reshaped according to a predetermined model, reset and then fixed. The surgical trauma is relatively large. Due to the dense distribution of oral and maxillofacial nerves, especially the trigeminal nerve, which plays a very important role in oral and maxillofacial sensation, the pain is obvious after orthognathic surgery. Especially for orthognathic surgery involving the mandible, because the mandible is denser and contains the inferior 
alveolar nerve, the third branch of the trigeminal nerve, the pain is more obvious after the mandibular orthognathic surgery [1,2]. At present, the clinical methods for postoperative analgesia after orthognathic surgery are mostly opioid-based intravenous self-controlled analgesia. Bilateral inferior alveolar nerve block combined with parecoxib sodium for postoperative analgesia is rarely reported in orthognathic surgery. The purpose of this study was to observe bilateral inferior alveolar nerve block combined with parecoxib sodium Multiple intravenous injection mode analgesia is used for the analgesic effect and safety of orthognathic surgery.

\section{Materials and Methods}

\section{Trial design and Oversight}

From February 2018 to February 2019, 40 patients in the Orthognathic Surgery Department of West China Stomatological Hospital of Sichuan University who planned to undergo mandibular sagittal splitting and genioplasty were included. All patients or their authorized agents signed informed consent. This experiment was approved by the Ethics Committee of West China Stomatological Hospital of Sichuan University.

\section{Inclusion criteria}

a) Age 18 to 45 years old, no gender limit, no brain dysfunction, able to cooperate and correctly understand Chinese, and express wishes;

b) American Association of Anesthesiologists (ASA) grade I to II.

\section{Exclusion criteria}

a) Preoperative maxillofacial neuropathological changes or maxillofacial surgery history or trauma history;

b) Long-term opioid use (daily or almost daily use of opioids for $>3$ months);

c) Alcohol or drug abuse, or those who are allergic to any medications (local anesthetics) used in this study.

d) Patients with sulfa allergy or a history of cardiovascular disease. Exclusion criteria, those who failed the nerve block or failed to complete the research for various reasons.

For patients who meet the inclusion criteria, they will be visited 1 day before surgery for pain education and pain scoring training.

\section{Randomization and Treatment}

On the day of surgery, all patients underwent general anesthesia, and induced intubation with propofol $2.0 \mathrm{mg} /$ $\mathrm{kg}$, sufentanil $0.2 \mu \mathrm{g} / \mathrm{kg}$, and cis-atracurium $0.2 \mathrm{mg} / \mathrm{kg}$.
Sufentanil $0.1 \mu \mathrm{g} / \mathrm{kg}$, cis- atracurium $0.05 \mathrm{mg} / \mathrm{kg}$, anesthesia maintenance remifentanil $0.1 \sim 0.3 \mu \mathrm{g} / \mathrm{kg} / \mathrm{min}$, cis-atracurium intermittent intravenous bolus before surgery, 1\% 3\% Sevoflurane is continuously inhaled. Random numbers were generated using SPSS software, and the patients were randomly divided into experimental group and control group on the day of surgery, with 20 cases in each group. In the experimental group, $0.1 \%$ ropivacaine was injected into bilateral inferior alveolar nerves via sagittal splitting and suture at the end of the operation, and parecoxib sodium $40 \mathrm{mg}$ was injected intravenously after the operation. The control group was connected to the intravenous analgesia pump $5 \mathrm{~min}$ before the end of the operation, and the loading dose was $3 \mathrm{~mL}$, the background dose was $5 \mathrm{~mL}$, the additional dose was $0.5 \mathrm{~mL}$, and the lock time was $20 \mathrm{~min}$. The analgesic pump is formulated to contain $100 \mu \mathrm{g}$ sufentanil and $10 \mathrm{mg}$ tropisetron.

\section{Outcome Measures}

Postoperatively, we evaluated and recorded the pain intensity of patients at 2, 4, 8, 24, and 48 h.If the patient did not tolerate pain, he was given an intravenous injection of parecoxib sodium $40 \mathrm{mg}$ and the total amount was recorded. The number and severity of analgesia-related adverse reactions such as respiratory depression, nausea and vomiting, dizziness, skin itching, and hypotension were recorded. For pain intensity, we use the Visual Analogue Scale (VAS), 0 points for painless and 10 points for unbearable pain. The sedation score uses Ramsay sedation score: 1 is divided into restlessness and irritability; 2 is divided into quiet and cooperative; 3 is divided into lethargy and can follow instructions; 4 is divided into sleep state and can be awakened; 5 is divided into slow arousal response; 6 points Deep sleep, not awake when calling.

\section{Statistical Analysis}

The data results were analyzed by SPSS 20.0 statistical software package. The measurement data of normal distribution were expressed as mean \pm standard deviation, and the comparison between groups was performed by $\mathrm{T}$ test. VAS scores and Ramsay scores were analyzed by anOVA with repeated measurements. Fisher exact probability method was used for counting data. Inspection level $\alpha=0.05$.

\section{Results}

\section{Patients}

Among the 40 patients included, 1 patient failed the nerve block, 1 patient refused to cooperate with the completion of the experiment 24 hours after the operation and was rejected. 
A total of 38 patients completed the experiment, 19 cases in each of the experimental group and the control group. There was no statistically significant difference in gender, age, and weight between the two groups ( $P>0.05$, Table 1$)$.

\begin{tabular}{|c|c|c|c|}
\hline Group & Gender(male/female) & Age & Weight (kg) \\
\hline Test group & $9 / 10$ & $25.21 \pm 6.10$ & $56.58 \pm 8.96$ \\
\hline Control group & $6 / 13$ & $22.47 \pm 3.99$ & $58.37 \pm 11.6$ \\
\hline $\mathrm{t}$ & & 1.635 & 0.501 \\
\hline $\mathrm{P}$ & 0.508 & 0.111 & 0.62 \\
\hline
\end{tabular}

Table 1: Comparison of general data of two groups of patients $n=19, x \pm s$.

\section{Pain Intensity and Ramsay Score}

As shown in table 2, pain intensity difference, no statistical significance between the groups $(\mathrm{F}=0.555$, $\mathrm{P}=0.461$ ), postoperative pain intensity difference was statistically significant different time points $(\mathrm{F}=48.611$, $\mathrm{P}=0.000$ ), and the interaction time and processing factors have no statistical significance $(F=2.672, P=0.059)$, and each time point compared differences between the groups had no statistical significance $(\mathrm{P}>0.05)$; There was no statistically significant difference in Ramsay scores between the two groups $(\mathrm{F}=2.885, \mathrm{P}=0.098)$, there was a statistically significant difference in Ramsay scores at different postoperative time points $(\mathrm{F}=8.891, \mathrm{P}=0.002)$, there was no statistically significant difference in the interaction between time and treatment factors $(\mathrm{F}=2.186, \mathrm{P}=0.138)$, and there was no statistically significant difference between the two groups at each time point $(\mathrm{P}>0.05)$.

\begin{tabular}{|c|c|c|c|c|c|c|c|c|}
\hline \multicolumn{4}{|c|}{ Postoperative time point } & \multicolumn{3}{c|}{ VAS score } & \multicolumn{2}{c|}{$\begin{array}{c}\text { Ramsay } \\
\text { score }\end{array}$} \\
\hline \multicolumn{2}{|c|}{$\begin{array}{c}\text { Experimental } \\
\text { group }\end{array}$} & $\begin{array}{c}\text { Control } \\
\text { group, }\end{array}$ & $\mathbf{t}$ & \multicolumn{2}{c|}{$\begin{array}{c}\text { Experimental } \\
\text { group }\end{array}$} & $\begin{array}{c}\text { Control } \\
\text { group }\end{array}$ & t & p \\
\hline $2 \mathrm{~h}$ & $3.11 \pm 0.73$ & $2.73 \pm 0.45$ & 1.856 & 0.072 & $2.11 \pm 0.31$ & $2.31 \pm 0.47$ & 1.60 & 0.118 \\
\hline & & & & & & & 4 & \\
\hline $4 \mathrm{~h}$ & $2.89 \pm 0.80$ & $2.47 \pm 0.61$ & 1.809 & 0.079 & $2.00 \pm 0.00$ & $2.05 \pm 0.22$ & 1.00 & 0.324 \\
\hline & & & & & & & 0 & \\
\hline $8 \mathrm{~h}$ & $2.68 \pm 0.61$ & $2.47 \pm 0.61$ & 0.897 & 0.376 & $2.00 \pm 0.00$ & $2.00 \pm 0.00$ & - & - \\
\hline $24 \mathrm{~h}$ & $1.47 \pm 0.96$ & $1.84 \pm 0.76$ & 1.305 & 0.200 & $2.00 \pm 0.00$ & $2.00 \pm 0.00$ & - & - \\
\hline $48 \mathrm{~h}$ & $1.42 \pm 0.90$ & $1.36 \pm 0.95$ & 0.175 & 0.862 & $2.00 \pm 0.00$ & $2.00 \pm 0.00$ & - & - \\
\hline
\end{tabular}

Table 2: Pain intensity and Ramsay score at each time point after operation in both groups $n=19, \pm$.

\section{Postoperative Complications and Adverse Reactions}

During the analgesia treatment, neither group of patients experienced respiratory depression, hypotension, or skin itching. The incidence of nausea and vomiting in the experimental group was $21 \%$ ( 4 cases), and the incidence of nausea and vomiting in the control group was 53\% (10 cases). The incidence of nausea and vomiting in the experimental group was lower than that in the control group, and the difference was statistically significant $(\mathrm{P}=0.046)$. The incidence of dizziness in the experimental group was $11 \%$ ( 2 cases), and the incidence of dizziness in the control group was $26 \%$ ( 5 cases). There was no significant difference in the incidence of dizziness between the experimental group and the control group $(\mathrm{P}=0.202)$.

\section{Discussion}

Orthognathic surgery patients have high expectations for the operation itself, the occurrence of pain and adverse reactions is not conducive to postoperative recovery, and the comfort is reduced [3]. Some scholars have studied the use of a variety of sedatives and analgesics (including midazolam, sufentanil, analgin, tramadol, etc.) for preoperative, intraoperative, and postoperative use to control postoperative pain after orthognathic surgery, But the effect is not good [4]. In recent years, a large number of studies have reported that intraoperative nerve block anesthesia can reduce the occurrence and intensity of postoperative pain after general anesthesia [5]. The results show that the effect of nerve block 


\section{Open Access Journal of Dental Sciences}

is far better than simple analgesics [6,7]. The use of nerve block anesthesia during general anesthesia has also been reported in oral and maxillofacial surgery, and the results also show that nerve block can significantly reduce surgical incision pain after general anesthesia [8]. However, in terms of postoperative analgesia after orthognathic surgery, there are no studies that clearly report the effect of nerve block anesthesia on postoperative pain after general anesthesia for orthognathic surgery [9]. Considering that the innervation of the mandible is relatively simple, it is relatively simple to use nerve block anesthesia to control pain after mandibular surgery. Therefore, this study is to observe patients who have only mandibular orthognathic surgery.

Ropivacaine is a long-acting amide local anesthetic [10] with a lower possibility of inducing cardiovascular and neurotoxicity [11,12], Božidar Brković, et al. [13] research confirmed that ropivacaine $(1 \%, 2 \mathrm{~mL})$ is effective for postoperative analgesia after inferior alveolar nerve block and has a long duration. Ogura, et al. [14] showed that $0.75 \%$ ropivacaine can effectively control pain when used for inferior alveolar nerve block during implant surgery. Chatellier, et al. [15] showed that bilateral inferior alveolar nerve block reduced the incidence of nausea and vomiting after mandibular sagittal osteotomy.

Parecoxib sodium is a selective cyclooxygenase-2 (Cyclooxygenase-2 COX-2) inhibitor, by selectively inhibiting the expression of $\mathrm{COX}-2$, inhibiting the production of prostaglandins to achieve analgesic effects $[16,17]$. Compared with non-COX-2 inhibitors, the incidence of gastrointestinal reactions is low, and it does not affect platelet aggregation and clotting time [18], and has achieved good results in postoperative analgesia of various operations.

In this study, the experimental group of patients used bilateral ropivacaine $(1 \%, 2 \mathrm{~mL})$ intraoperative inferior alveolar nerve block anesthesia, postoperative combined with parecoxib sodium multimodal analgesia, the control group used Patient controlled intravenous analgesia (sufentanil + tropisetron). The results showed that the two analgesic modes of the experimental group and the control group both had a very good analgesic effect on patients' postoperative analgesia. The two groups of patients used the same anesthesia plan during the operation, and there was no significant difference in the amount of opioid used. There was no significant difference in the VAS pain score and Ramsay sedation score of the two groups at each observation point after the operation ( $\mathrm{P}>0.05)$. It shows that the analgesic effects of the two analgesic methods are equivalent. Orthognathic surgery can easily cause vagus nerve hyperactivity and reflex nausea and vomiting due to the particularity of the surgical site $[19,20]$. Swallowing a large amount of blood during the operation and the side effects of general anesthetics can cause nausea and vomiting to varying degrees. In this study, in order to reduce the incidence of vomiting caused by intraoperative secretions and blood swallowing, all patients were filled with pharyngeal cavity sand strips during the operation to prevent intraoperative blood and secretions from being swallowed into the stomach. In this study, 19 patients in the experimental group had nausea and vomiting in 4 cases and dizziness in 2 cases during follow-up. In the control group of 19 patients, 10 cases of nausea and vomiting and 5 cases of dizziness occurred during the postoperative follow-up. The incidence of adverse reactions in the experimental group was lower than that in the control group.

\section{Conclusion}

In summary, for orthognathic patients, bilateral inferior alveolar nerve block (1\% ropivacaine) combined with intravenous analgesia with parecoxib sodium has a considerable analgesic effect than simple intravenous analgesia. However, the incidence of postoperative adverse reactions is significantly lower, which is worthy of clinical application.

\section{References}

1. Mobini A, Mehra P, Chigurupati R (2018) Postoperative pain and opioid analgesic requirements after orthognathic surgery. J Oral Maxillofac Surg 76(11): 2285-2295.

2. Chen CM, Lai S, Chen KK, Lee HE (2015) Intraoperative hemorrhage and postoperative sequelae after intraoral vertical ramus osteotomy to treat mandibular prognathism. Biomed Res Int 2015: 318270.

3. Phillips C, Kiyak HA, Bloomquist D, Turvey TA (2004) Perceptions of recovery and satisfaction in the short term after orthognathic surgery. J Oral Maxillofac Surg 62(5): 535-544.

4. Raschke GF, Meissner W, Peisker A, Djedovic G, Rieger U, et al. (2018) Bilateral sagittal split osteotomy-parameters and correlations of postoperative pain management. Clin Oral Investig 22(1): 181-187.

5. Wojtyś ME, Wąsikowski J, Wójcik N, Wojcik J, Wasilewski P, et al. (2019) Assessment of postoperative pain management and comparison of effectiveness of pain relief treatment involving paravertebral block and thoracic epidural analgesia in patients undergoing posterolateral thoracotomy. J Cardiothorac Surg 14(1): 78.

6. Bakshi SG, Shetmahajan M, Thota RS (2019) Pectoralis block for breast surgeries: more than postoperative 


\section{Open Access Journal of Dental Sciences}

analgesic. Indian J Anaesth 63(3): 243-245.

7. Hong S, Kim H, Park J (2019) Analgesic effectiveness of rectus sheath block during open gastrectomy: a prospective double-blinded randomized controlled clinical trial. Medicine (Baltimore) 98(15): e15159.

8. Parameswaran A, Ganeshmurthy MV, Ashok Y, Ramanathan M, Markus AF, et al. (2018) Does sphenopalatine ganglion block improve pain control and intraoperative hemodynamics in children undergoing palatoplasty? A randomized controlled trial. J Oral Maxillofac Surg 76(9): 1873-1881.

9. Nagatsuka C, Ichinohe T, Kaneko Y (2000) Preemptive effects of a combination of preoperative diclofenac, butorphanol, and lidocaine on postoperative pain management following orthognathic surgery. Anesth Prog 47(4): 119-124.

10. Rao KG, Misra S, Shukla A (2017) Comparison between epidural ropivacaine versus ropivacaine with clonidine in patients undergoing abdominal hysterectomy: a randomized study. Anesth Essays Res 11(2): 334-339.

11. Mcclellan J, Faulds D (2000) Ropivacaine: an update of its use in regional anaesthesia. Drugs, 60(5): 1065-1093.

12. Schwoerer AP, Scheel H, Friederich P (2015) A comparative analysis of bupivacaine and ropivacaine effects on human cardiac SCN5A channels. Anesth Analg 120(6): 1226-1234.

13. Brković B, Andrić M, Ćalasan D, Milic M, Stepic J, et al. (2017) Efficacy and safety of 1\% ropivacaine for postoperative analgesia after lower third molar surgery: a prospective, randomized, double-blinded clinical study. Clin Oral Investig 21(3): 779-785.

14. Ogura S, Shinohara K, Sunada K, Takamori H, Nakamura
K (2008) A randomized controlled trial comparison between ropivacaine and 2\%lidocaine containing adrenalin for inferior alveolar nerve block during implant surgery. Oral Therapeut Pharmacol 27(2): 125130.

15. Chatellier A, Dugué AE, Caufourier C, Maksud B, Compere JF, et al. (2012) Inferior alveolar nerve block with ropivacaine: effect on nausea and vomiting after mandibular osteotomy. Rev Stomatol Chir Maxillofac 113(6): 417-422.

16. Camu F, Borgeat A, Heylen RJ, Viel EJ, Boye ME, et al. (2017) Parecoxib, propacetamol, and their combination for analgesia after total hip arthroplasty: a randomized non-inferiority trial. Acta Anaesthesiol Scand 61(1): 99110.

17. Schug SA, Parsons B, Li CM, Xia F (2017) The safety profile of parecoxib for the treatment of postoperative pain: a pooled analysis of 28 randomized, double-blind, placebo-controlled clinical trials and a review of over 10 years of postauthorization data. J Pain Res 10(10): 24512459.

18. Bian YY, Wang LC, Qian WW, Lin J, Jin J, et al. (2018) Role of parecoxib Sodium in the multimodal analgesia after total knee arthroplasty: a randomized double-blinded controlled trial. Orthop Surg 10(4): 321-327.

19. Laskin DM, Carrico CK, Wood J (2020) Predicting postoperative nausea and vomiting in patients undergoing oral and maxillofacial surgery. Int J Oral Maxillofac Surg 49(1): 22-27.

20. Dobbeleir M, De Coster J, Coucke W, Politis C (2018) Postoperative nausea and vomiting after oral and maxillofacial surgery: a prospective study. Int J Oral Maxillofac Surg 47(6): 721-725. 